\title{
MODELO DE GEOPROCESSAMENTO PARA TOMADA DE DECISÃO SOBRE ARRENDAMENTO DE TERRAS NO CULTIVO DE CANA-DE-AÇÚCAR
}

\author{
ARRUDA, Carina Carlos ${ }^{1}$ \\ ROSALEN, David Luciano ${ }^{2}$
}

\begin{abstract}
Recebido em: 2020.04 .28
Aprovado em: 2020.06.25

ISSUE DOI: $10.3738 / 1982.2278 .3792$

RESUMO: Os estudos de viabilidade simulam a exploração da área, de acordo com a modalidade produtiva mais vantajosa, conforme diversas características da área - Proximidade à usina, declividade do terreno e histórico da área. O trabalho visa contribuir com ferramentas de geotecnologia, com o desenvolvimento de um sistema que auxilie na tomada de decisão de arrendamento de terras para fornecimento de cana, utilizando-se de um estudo de caso. A área está localizada em Dobrada - SP, próximo às coordenadas geográficas $21^{\circ} 32^{\prime} 17,3$ ”'S e $48^{\circ} 22^{\prime} 47,4$ '”W. A região abrange aproximadamente 13 ha cultivados com cana-de-açúcar. Após a correta demarcação dos talhões, foi possível identificar a área de interesse, que foi exportada para o QGIS 2.18.23, onde se pode gerar o perímetro. Foi criada uma ferramenta para otimização do processo e, definido os limites geográficos, processou-se os polígonos, interpolando os resultados e, então, gerou-se os mapas. A ferramenta conseguiu criar com sucesso o estudo da área, podendo auxiliar a tomada de decisão estratégica em projetos de renovação e expansões de áreas.
\end{abstract}

Palavras-chave: SIG; Arrendamento rural. Estudos de viabilidade.

\section{GEOPROCESSING MODEL FOR DECISION MAKING ON LAND LANDING IN SUGARCANE CULTIVATION}

\begin{abstract}
SUMMARY: Feasibility studies simulate the exploration of the area, according to the most advantageous productive modality, according to several characteristics of the area - proximity to the plant, slope of the land and history of the area. The work aims to contribute with geotechnology tools, with the development of a system that assists in the decision making of land leasing for sugarcane supply, using a case study. The area is located in Dobrada-SP, near the geographic coordinates $21^{\circ} 32^{\prime} 17,3^{\prime}$ S and $48^{\circ} 22^{\prime} 47,4^{\prime \prime} \mathrm{W}$. The region covers approximately 13 ha grown with sugar cane. After the correct demarcation of the plots, it was possible to identify the area of interest, which was exported to QGIS 2.18.23, where its perimeter was generated. A process optimization tool was created, defining the geographical boundaries, processing the polygons, interpolating the results and then generating the maps. The tool was able to successfully generate the study of the area and can assist strategic decision making in area renovation projects or even in expansions.
\end{abstract}

Keywords: Rural lease. Feasibility studies. Suppliers.

\section{INTRODUÇÃO}

O plantio da cana-de-açúcar iniciou-se no período colonial, sendo hoje uma das principais culturas agrícolas da economia brasileira. O Brasil é responsável por mais da metade de todo o açúcar comercializado mundialmente, e também o maior exportador de etanol. Essa produção tem colaborado para o desenvolvimento de novas tecnologias e aumento de usinas em todo o país, trazendo muitos benefícios, como emprego e renda para a população e para empresas sucroalcooleiras.

\footnotetext{
${ }^{1}$ Engenheira Florestal (2015) pela UFSCar, Engenheira de segurança e especialista em Georreferenciamento de imóveis rurais pela Fatep.

${ }^{2}$ Faculdade de Ciências Agrárias e Veterinárias de Jaboticabal
} 
Para se ter acesso a matéria-prima, as unidades produtoras utilizam se sua produção (terras próprias), produção própria em áreas arrendadas (administração e a condução da produção é responsabilidade da unidade produtora), produção por fornecimento (o fornecedor é quem lida com o melhor arranjo para produção da matéria-prima) e compra à vista ou compra "Sppot".

Os estudos de arrendamento destinam-se a simular a exploração da área, de acordo com a modalidade produtiva mais vantajosa para a empresa, conforme um valor a ser estipulado. Esse valor pode variar conforme as seguintes características da área: proximidade à usina, declividade do terreno e histórico da área.

Neste contexto, o presente trabalho objetivou, utilizando de ferramentas de geoprocessamento, contribuir com uma metodologia que auxilie na tomada de decisão de arrendamento de terras para fornecimento de cana-de-açúcar, demonstrando sua eficácia através de um estudo de caso.

\section{REVISÃO DE LITERATURA}

No Brasil, a cultura de cana-de-açúcar é uma das mais importantes do país, tanto pela área que ocupa como do ponto de vista econômico, ambiental e social. Além das características climáticas favoráveis a sua produção e do desenvolvimento da indústria sucroalcooleira que é referência tanto no aspecto tecnológico como de gestão do negócio, o cultivo da cana tem sido alavancada pelos baixos custos de produção do açúcar e do etanol, e pelas condições favoráveis de preço no mercado internacional, bem como a maior demanda por este combustível no mercado interno e externo.

Um dos principais benefícios do Brasil em desenvolver esse cultivar foi diminuir a dependência de combustíveis fósseis. Quando se observa os diversos tipos de custos envolvendo a produção do etanol, verifica-se que este biocombustível é relativamente mais barato do que o produzido nos Estados Unidos e na Alemanha. Ressalta-se que uma unidade de etanol derivado da cana-de-açúcar gera uma quantidade de energia equivalente a 9,3 unidades de energia de combustível fóssil, enquanto que os provenientes do trigo e da beterraba correspondem a duas unidades de energia de combustível fóssil; já o etanol do milho corresponde a 1,4 unidades de energia de combustível fóssil (KOHLHEPP, 2010). Portanto, o balanço energético do etanol brasileiro é quase cinco vezes mais eficiente do que o etanol derivado do açúcar de beterraba e quase sete vezes melhor do que o etanol de milho.

Ainda cabe ressaltar que a vantagem competitiva possuída pelo Brasil não deriva apenas da própria cultura da cana-de-açúcar e no clima brasileiro, mas também fruto de um intenso 
investimento em pesquisa e tecnologia por parte de instituições de pesquisa, que conseguiram identificar e aplicar novas e eficientes técnicas voltadas para todo o ciclo de produção de cana-deaçúcar, desde o setor agrícola, como o setor industrial (CARLESSO NETO; VERÍSSIMO, 2018).

O Estado de São Paulo segue como o principal produtor nacional de cana-de-açúcar, com $57,1 \%$ da área ou 4,69 milhões de hectares. Na sequência, aparecem: Goiás (9,3\%); Minas Gerais (8,9\%); Mato Grosso do Sul (7,4\%); e Paraná (6,7\%) (NOVA CANA, 2014). De um modo geral, o arrendamento de terras nada mais é do que um aluguel de áreas para a produção. Esta modalidade é uma realidade em diversas regiões produtivas, sendo incorporado nos custos de produção, podendo, inclusive, assumir parcela significativa no custo operacional de produção. As estruturas de governança observadas nas transações de cana-de-açúcar no Oeste Paulista variam desde a estrutura mais verticalizada - a integração vertical total (cana produzida em terras da própria usina) - até a de menor controle pelas usinas - o mercado spot (compra sem contrato ou compromisso). Esses conjuntos de estruturas de governança podem ser agrupados em:

1. Cana-de-açúcar produzida em parceria: o proprietário cede a terra para a usina e recebe por ela uma parcela da cana que foi produzida. Nessa forma não há a incidência do Imposto de Renda sobre propriedade, reduzindo a carga tributária sobre a usina e também sobre o proprietário da terra;

2. Cana-de-açúcar proveniente de acionistas da usina (com ou sem contratos): pode haver ou não contrato e fornece certo grau de garantia para as usinas, já que é do interesse do acionista que a produtora tenha elevado nível de lucratividade;

3. Contratos com fornecedores que não possuem participação acionária: a usina firma contrato com os fornecedores de cana-de-açúcar por prazo determinado. Nessas estruturas de governança intermediárias - ou híbridas - a forma de pagamento, as responsabilidades (preparo do solo, plantio, tratos culturais, corte, carregamento, transbordo e transporte), a disponibilidade de assistência técnica e a duração dos contratos são diferenciadas entre as usinas e também entre as transações em uma mesma, o que dá às transações uma variedade significativa, dificultando a organização de um número fixo de arranjos.

Com o intuito de restringir os investimentos iniciais e a imobilização de capitais em terras, as usinas têm preferido o arrendamento de terras (opção 3, vide acima). Os proprietários das áreas, por sua vez, em busca de maior rendimento econômico, têm facilitado e aderido ao arrendamento, como base de tal expansão. $\mathrm{O}$ arrendamento evita que as usinas se comprometam com a terra cultivada em longo prazo, se afirmando frente às incertezas econômicas no futuro. No planejamento agrícola visando à remuneração do capital em tempo mais rápido, o arrendamento representa o meio mais eficiente, visto que se baseia em uma cultura semiperene, trazendo rápido 
retorno ao produtor. Ressalta-se ainda, que os valores de arrendamento são utilizados como direcionadores para estimar o custo de oportunidade, partindo-se da premissa que caso o produtor não estivesse produzindo, arrendaria conforme os valores pagos na região específica (Confederação da Agricultura e Pecuária do Brasil, 2017).

O processo de produção dá por início na elaboração do contrato de arredamento para então realizar-se os tratos necessários para o plantio. No contrato, o proprietário, também denominado arrendador, cede ao arrendatário o uso do imóvel rural para atividade agrícola, não tendo nenhuma influência nos custos de produção, despesas ou prejuízos da atividade para a qual arrendou as terras.

O sistema de pagamentos pode variar de diversas formas, desde litros de álcool por tonelada de cana, quilograma de ATR (Açúcares totais redutores) por tonelada de cana (ATR fixo), ATR relativo, ATR apurado, entre outros. Há usinas que optam por um determinado sistema, outras que possuem mais de um e algumas que fecham contratos flexíveis, nos quais o contratado escolhe qual parcela da produção deve receber sob qual forma de pagamento, sempre considerando o preço de $1 \mathrm{~kg}$ de ATR apurado pelo Conselho dos Produtores de Cana-de-açúcar, Açúcar e Álcool do estado de São Paulo - CONSECANA (CONSECANA, 2006). Conforme levantamentos realizados pelo Instituto de Economia Agrícola - IEA, apurou-se que a quantidade fixa paga foi, em média 18,8 $\mathrm{t} \mathrm{ha}^{-1}$ no Estado de São Paulo (IEA, 2012). Na maioria dos contratos de arrendamento utiliza-se o ATR da cana padrão, de 121,97 mg ha ${ }^{-1}$ (CNA, 2017), o produto entre o valor de precificação do ATR, com as grandezas expressas anteriormente resulta nos valores dispendidos por hectare. Em algumas regiões do Estado de São Paulo, as usinas pagam até $\mathrm{R} \$ 1.780$ por hectare, gerando $10,6 \%$ de rentabilidade.

O tempo de duração dos contratos é atribuído de acordo com a idade do canavial. Quanto mais novo, maior é a duração do contrato. Há uma pequena variação entre as usinas na determinação desse ínterim, em que temos: 1 (um para reforma) ou 5-6 (cinco ou seis para colheita) anos. Essa variação dependerá da avaliação sobre as condições do canavial em produzir com uma qualidade aceitável para processamento e da disponibilidade para a realização da reforma.

As responsabilidades sobre preparo do solo, plantio, tratos culturais, corte, carregamento e transporte irão depender da tradição dos fornecedores, habilidades com a cultura e de sua capacidade financeira de arcar com o investimento necessário. Caso seja necessária a mecanização das áreas, a usina é responsável por corte, carregamento, transbordo e transporte, pois o investimento nos equipamentos é impeditivo para o fornecedor realizar essas atividades; porém, as despesas de transporte é por conta do fornecedor, que serão descontadas no ato do 
pagamento pela cana recebida. Em outros casos, há formação de condomínios de fornecedores, que constituem um agrupamento com uma estrutura administrativa própria, em que participam Técnicos Agrícolas e Engenheiros Agrônomos, responsáveis por orientar o preparo do solo, os tratos culturais e a recomendação varietal, retirando estas custas da usina. Em alguns casos, o condomínio possui o equipamento e o maquinário de Corte, Colheita e Transporte, reduzindo ainda mais os gastos operacionais da usina.

Destaca-se que, em termos de planejamento, adota-se a distância média de $40 \mathrm{~km}$ das usinas até os canaviais, a qual varia conforme o mercado. Esse raio de busca é válido para momentos em que o mercado encontra-se com relativa estabilidade entre oferta e procura. Devido ao baixo valor agregado da carga em relação ao frete, a cana-de-açúcar não pode ser transportada a longas distâncias. Portanto, esse distanciamento adotado é economicamente viável para a concorrência por terras e fornecedores. Desta forma, o correto estudo da área, entrelaçando as variáveis, é de extrema importância para a tomada de decisão dos gestores das áreas agrícolas das unidades produtoras.

\section{MATERIAL E MÉTODO}

Foi proposta uma metodologia para auxiliar na tomada de decisão no processo de seleção de glebas agrícolas, para fins de arrendamento de terras para fornecimento de cana-de-açúcar.

Para avaliar a metodologia proposta, esta foi aplicada numa área localizada dentro dos limites políticos da cidade de Dobrada - SP, situada na Mesorregião de Ribeirão Preto, sendo situada próxima às coordenadas geográficas de $21^{\circ} 32^{\prime} 17,3^{\prime \prime} \mathrm{S}$ e $48^{\circ} 22^{\prime} 47,4$ ”'W. A região abrange uma área de aproximadamente 13 ha, cultivados exclusivamente com cana-de-açúcar.

Foi utilizado software Google Earth para identificar e delimitar a área de interesse. O polígono delimitado foi exportado para o software QGIS 2.18.23 e neste foram realizadas as operações de geoprocessamento conforme a metodologia proposta.

\section{RESULTADO E DISCUSSÃO}

O fluxograma da metodologia proposta para auxiliar na tomada de decisão na seleção de áreas, para o arrendamento de terras, é apresentado na Figura 1. 
Figura 1- Fluxograma para o estudo de arrendamento.

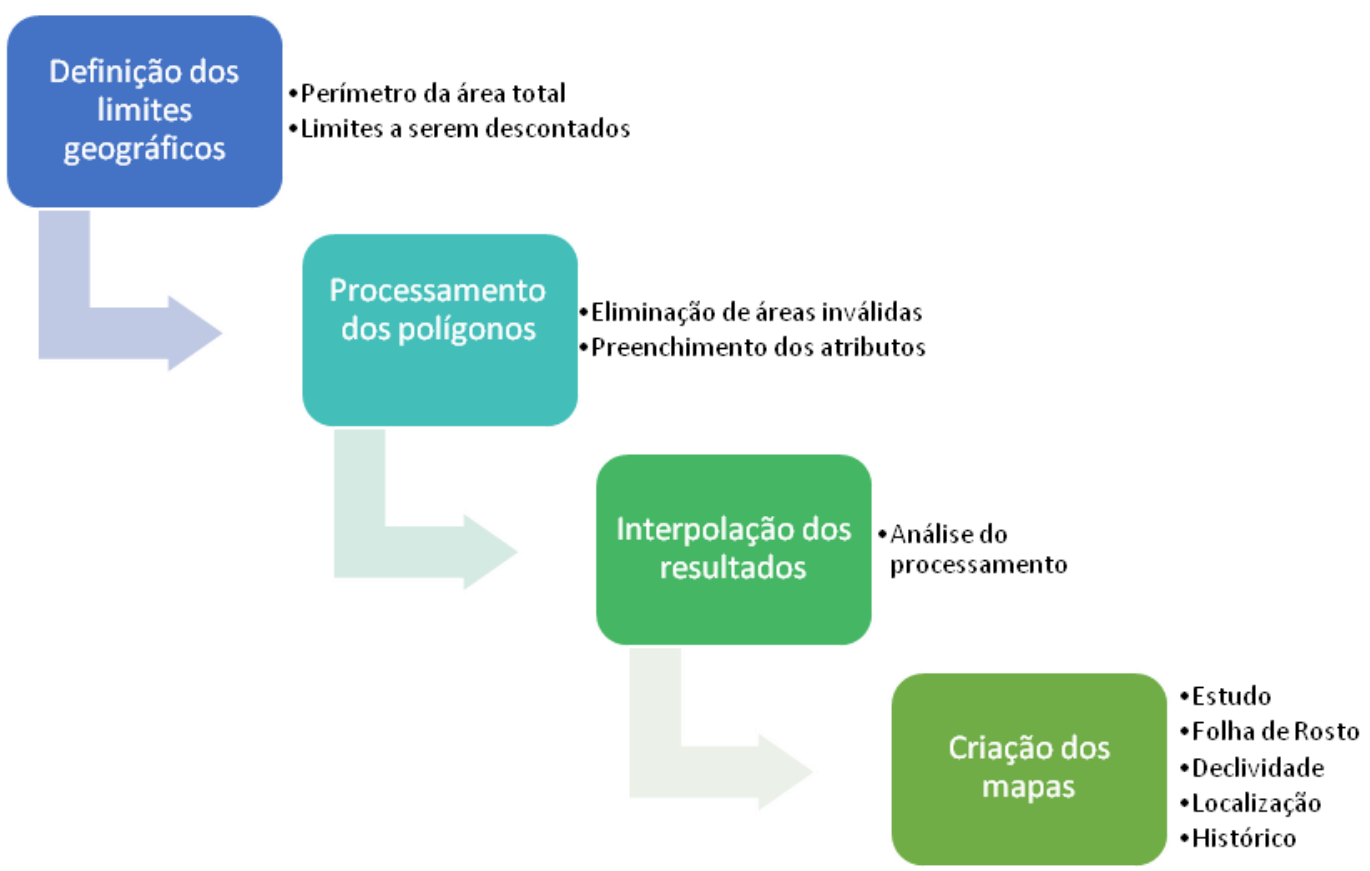

Fonte: Elaborado pelo Autor.

Após o estabelecimento da metodologia, houve a aplicação na área de estudo, para verificar sua viabilidade, conforme descrito abaixo.

Com as ferramentas ofertadas pelo software Google Earth, foi possível identificar e delimitar a área de interesse, indicada previamente pelo Gestor de fornecedores de cana. O polígono foi então exportado para o software QGIS 2.18.23, onde se gerou o perímetro da área (gtotal). Por meio do comando Buffers e seguindo as medidas pré-determinadas pela empresa (carreador externo - 2,5m e carreador interno - 2,0m), delimitou-se os carreadores e a Área de Preservação Permanente - APP nos cursos d’água (3,0m). Posteriormente, gerou-se um centróide para cada talhão, denominado de Talhao_text, com um número CHAVESIG (identificador individual de área no repositório de propriedades).

Para definir os limites geográficos, foram inseridas as camadas fixas (Rodovias, Perímetros urbanos, Google Satélite, Base de Talhões da companhia, distância da usina, unidades, declividades maiores que 36\%, além de áreas de amortecimento, de preservação permanente, zoneamento ambiental) (Figura 2); também, elaborou-se uma planilha geral contendo todas as CHAVESIG da empresa. 
Figura 2 - Delimitação dos limites geográficos da área em estudo.

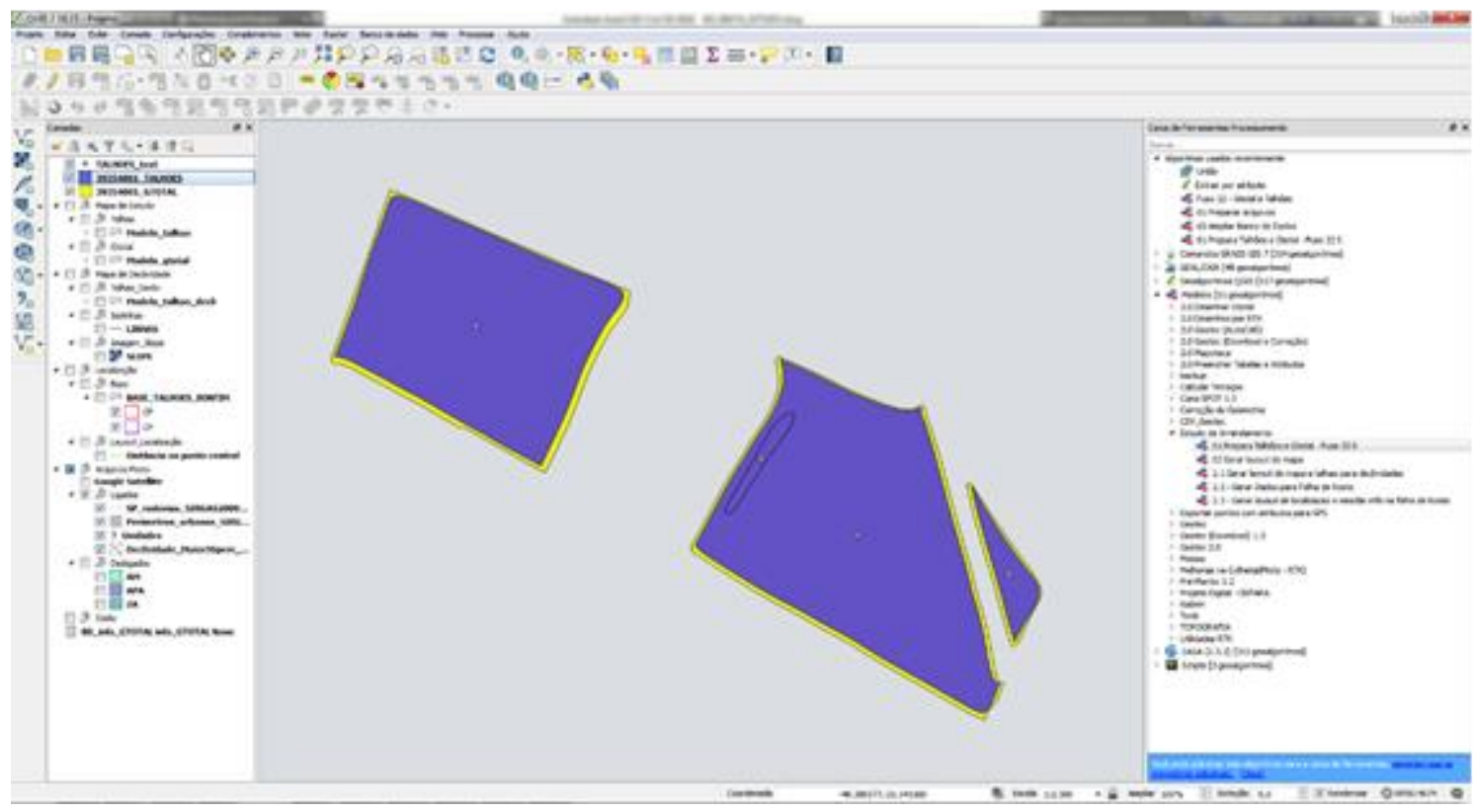

Fonte: Elaborado pelo Autor.

A partir dos dados, criou-se uma ferramenta para otimização do processo, por meio de dois passos. De início, preparou-se os talhões e o Gtotal, eliminando polígonos e locais inválidos, preenchendo os atributos das camadas com os dados da propriedade, tais como denominação, proprietário e município.

Então se inseriu as camadas na ferramenta, conforme a Figura 3. 
Figura 3 - Processamento para preparo de talhões.

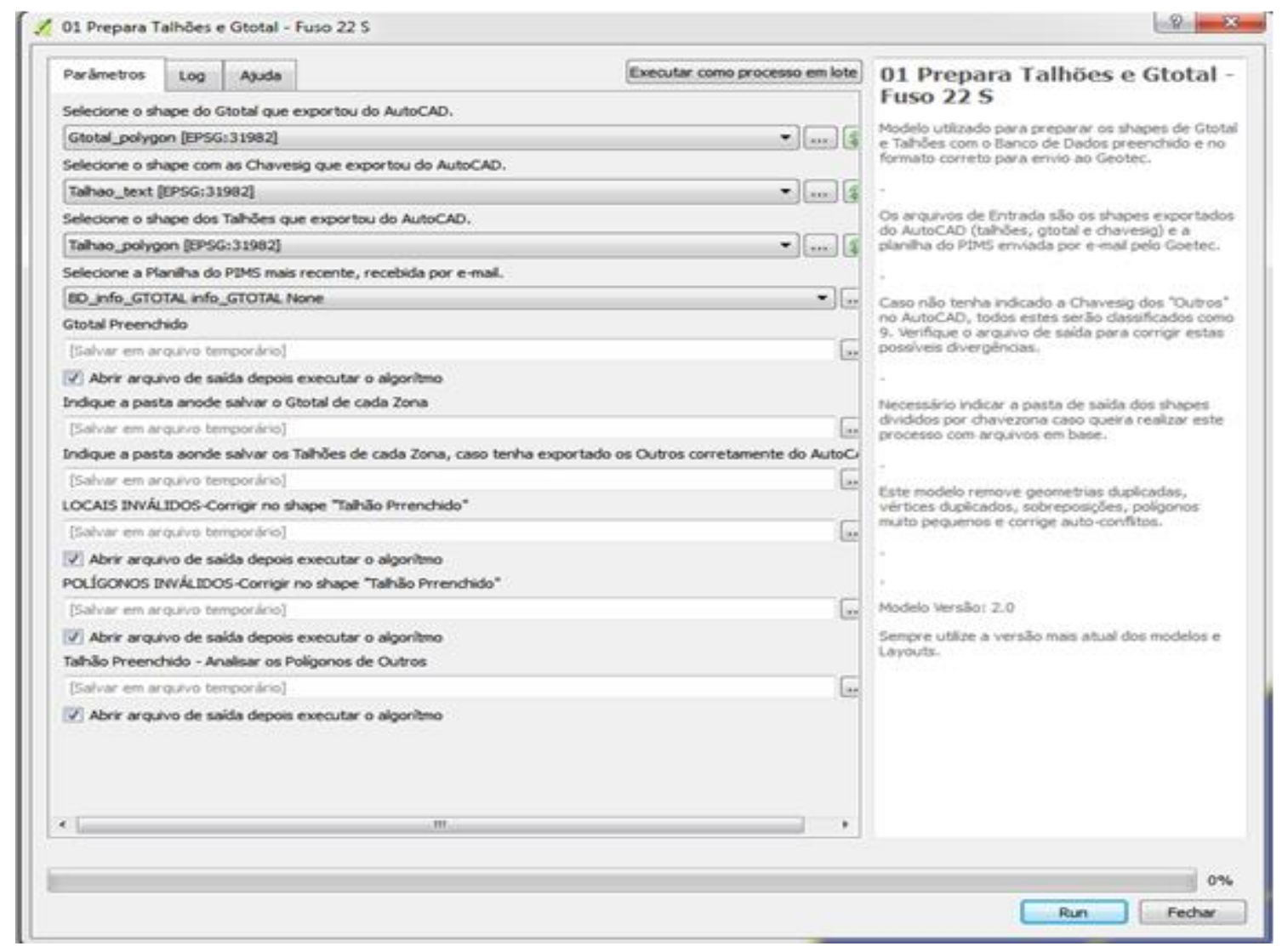

Fonte: Elaborado pelo Autor.

Foram então geradas as camadas com os locais inválidos (a verificar), os polígonos inválidos (a verificar), talhão preenchido e gtotal preenchido. Feitas as verificações, eliminamos as camadas de locais e polígonos inválidos. A seguir, criamos o modelo para gerar o Layout do mapa. Então cruzamos as informações, processando as camadas de perímetro (gtotal), talhões, zona de amortecimento, área de preservação ambiental, zoneamento ambiental, unidades e perímetros urbanos, conforme a Figura 4. 
Figura 4 - Processamento para o preparo do leiaute do mapa.

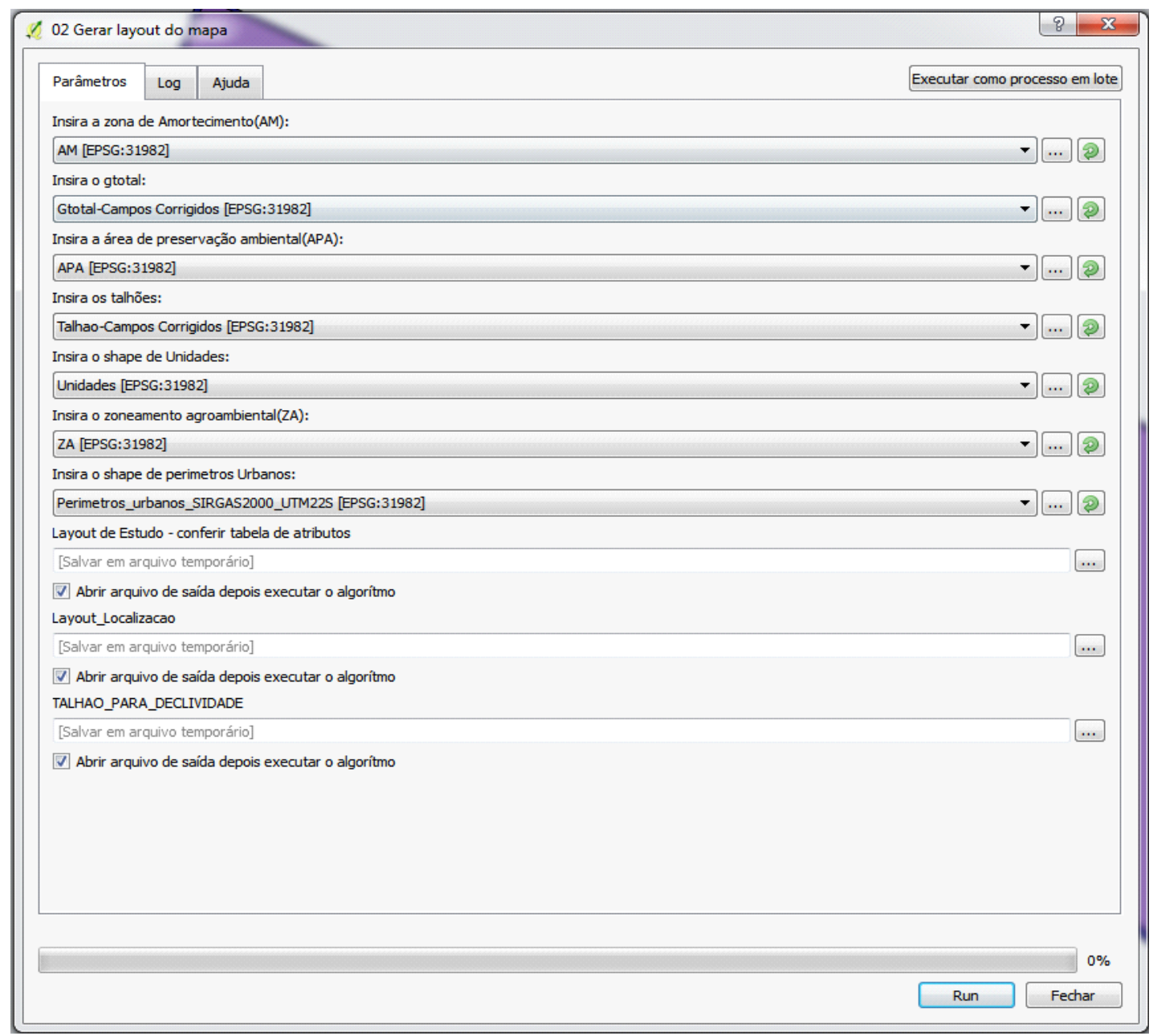




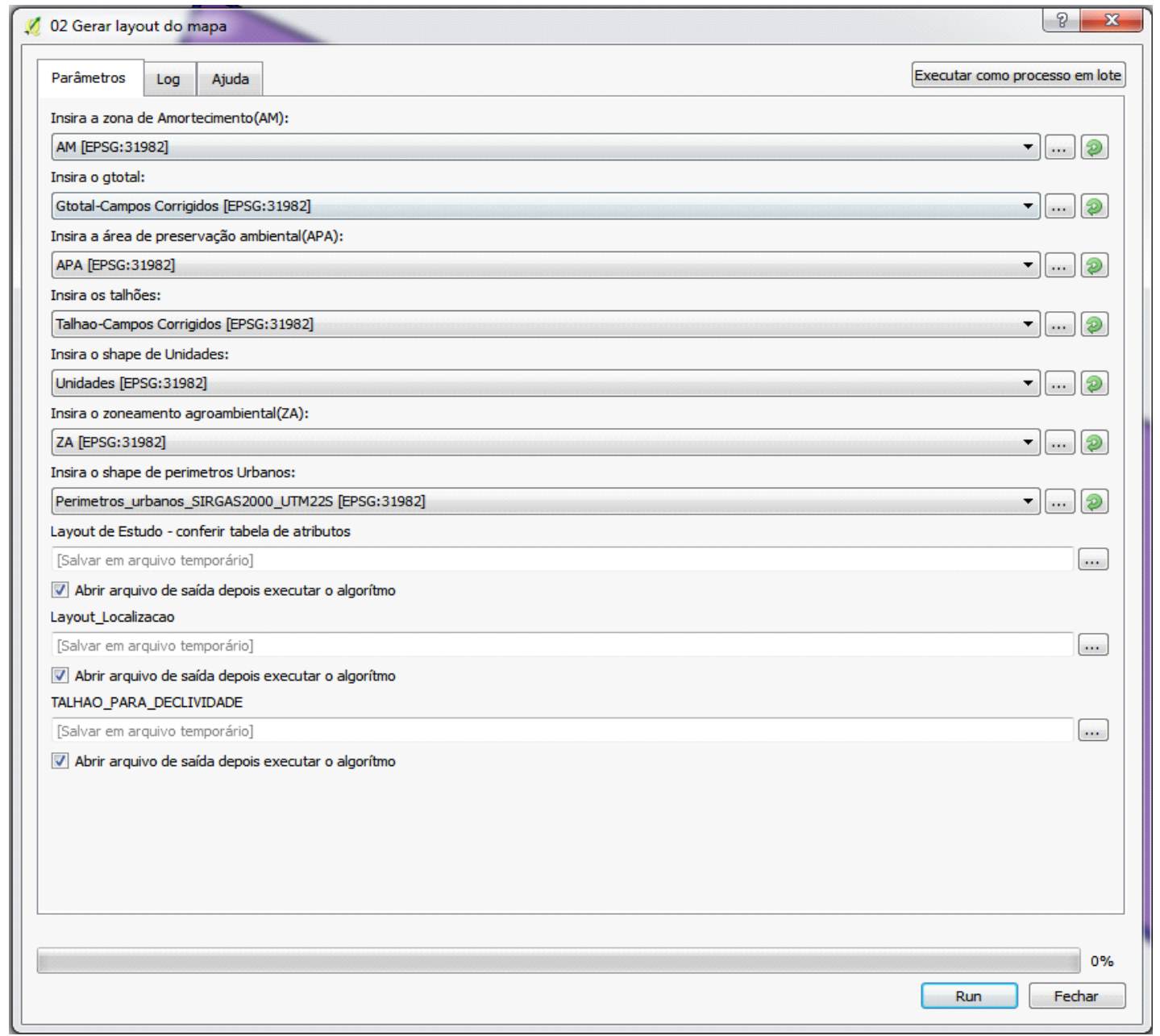

Fonte: Elaborado pelo Autor.

Gerou-se as camadas com o leiaute de estudo, leiaute de localização e talhão para declividade, sempre nos atentando para a verificação dos atributos das camadas geradas, já que servirão de atlas para gerarmos os mapas automatizados do Estudo de arrendamento.

De posse das camadas de cobertura, gerou-se os mapas de Estudo (Figura 5), Localização (Figura 6), Declividade (Figura 7) e Histórico da área (Figura 8), além da folha de Rosto - Laudo (Figura 9), com o auxílio de compositor de impressão individual, selecionado o respectivo atlas gerado na etapa anterior. 
Figura 5 - Mapa de estudo da propriedade localizada no município de Dobrada-SP.

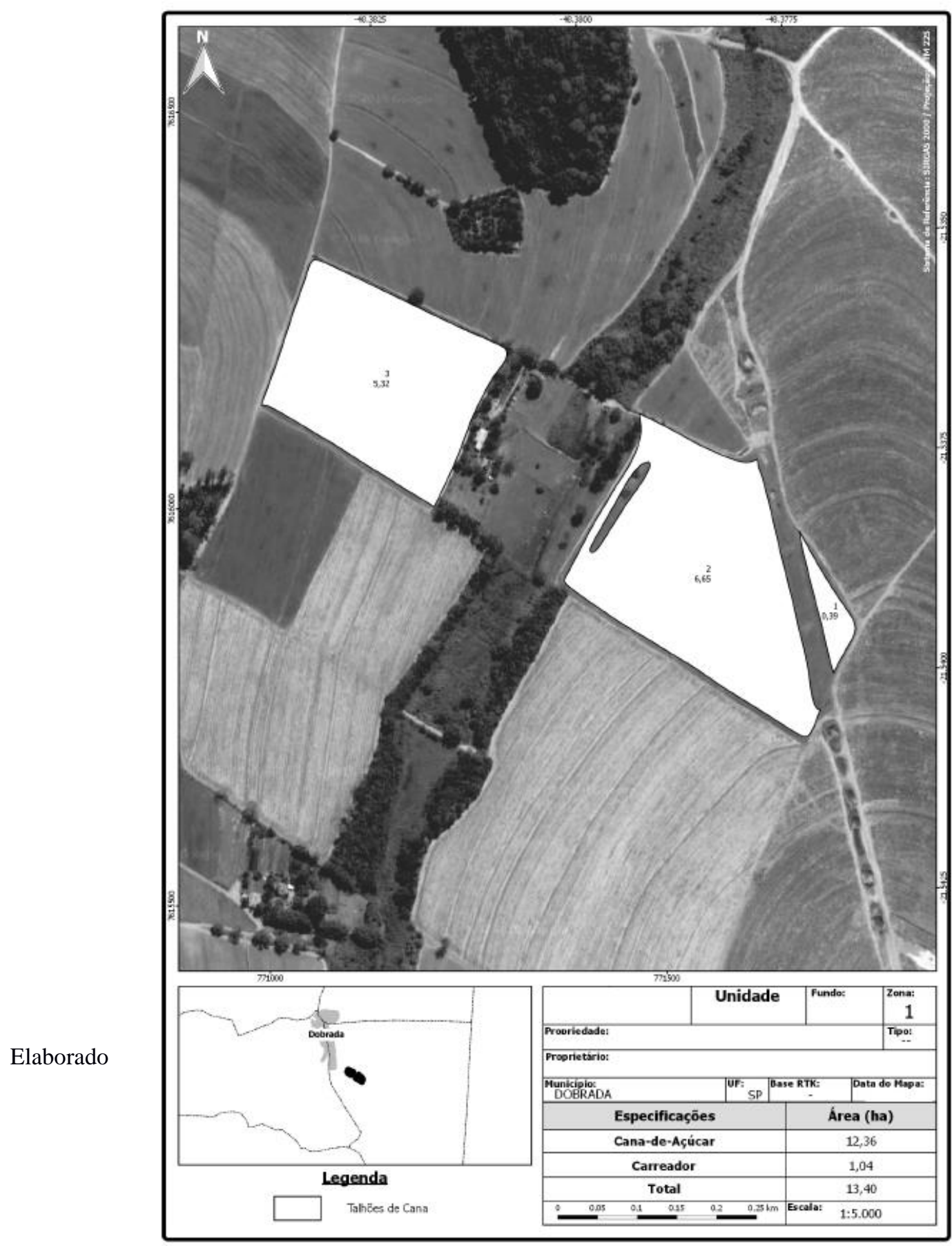

Fonte:

pelo Autor 
Figura 6 - Mapa de localização e distância até a usina.

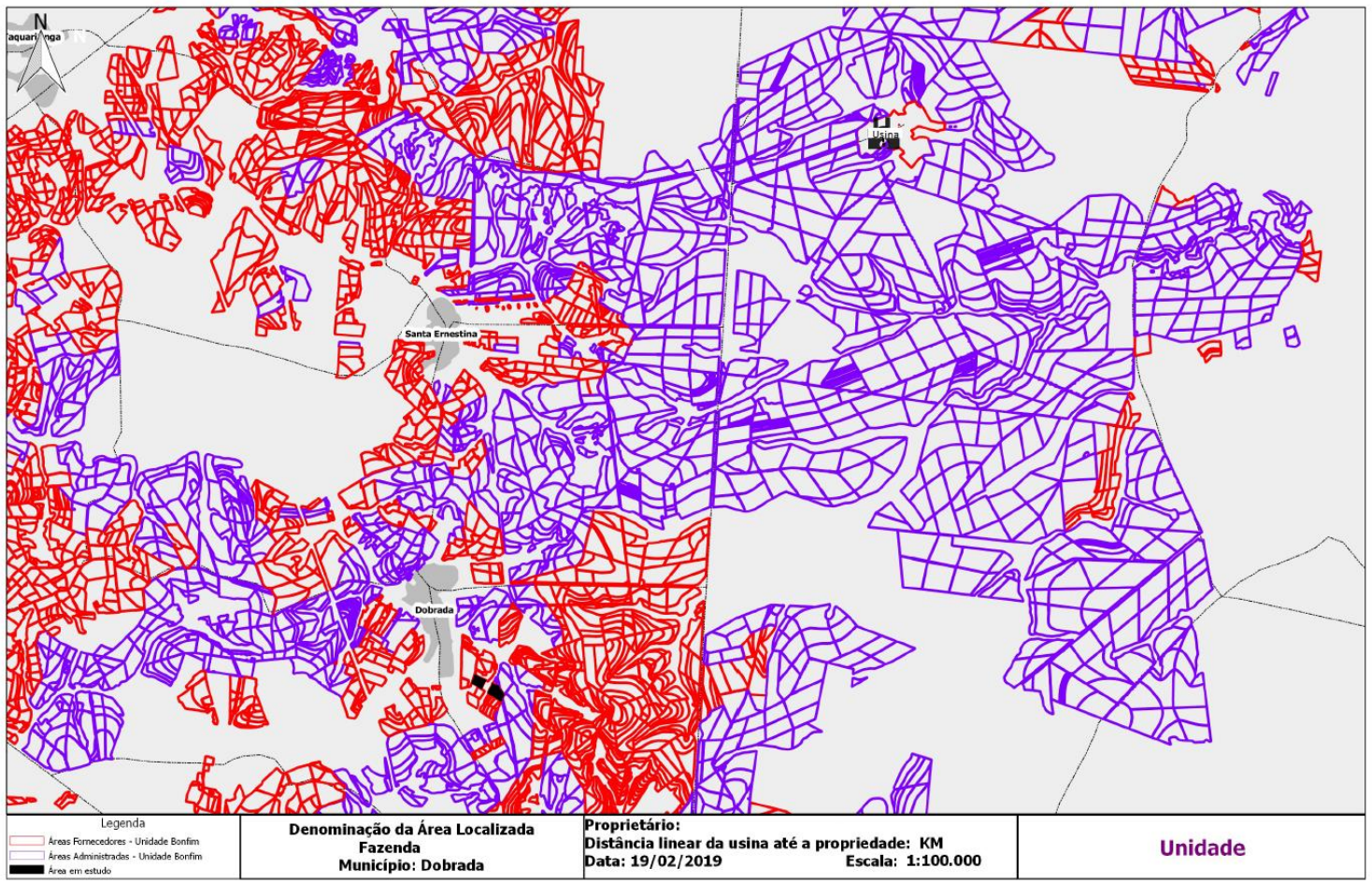

Fonte: Elaborado pelo Autor.

Figura 7 - Mapa de declividade da propriedade.

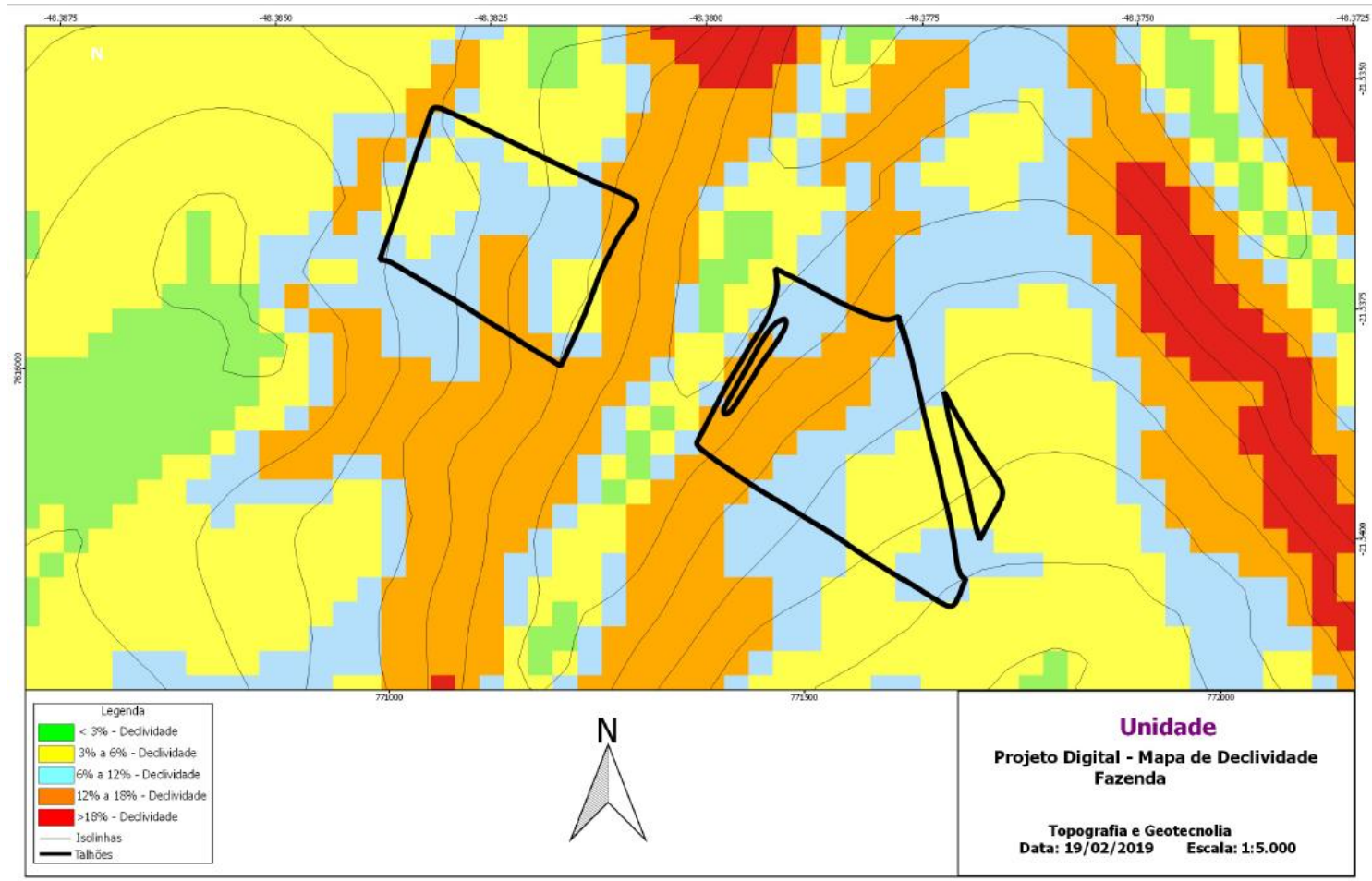

Nucleus, v.17, n.2, out. 2020 
Fonte: Elaborado pelo Autor.
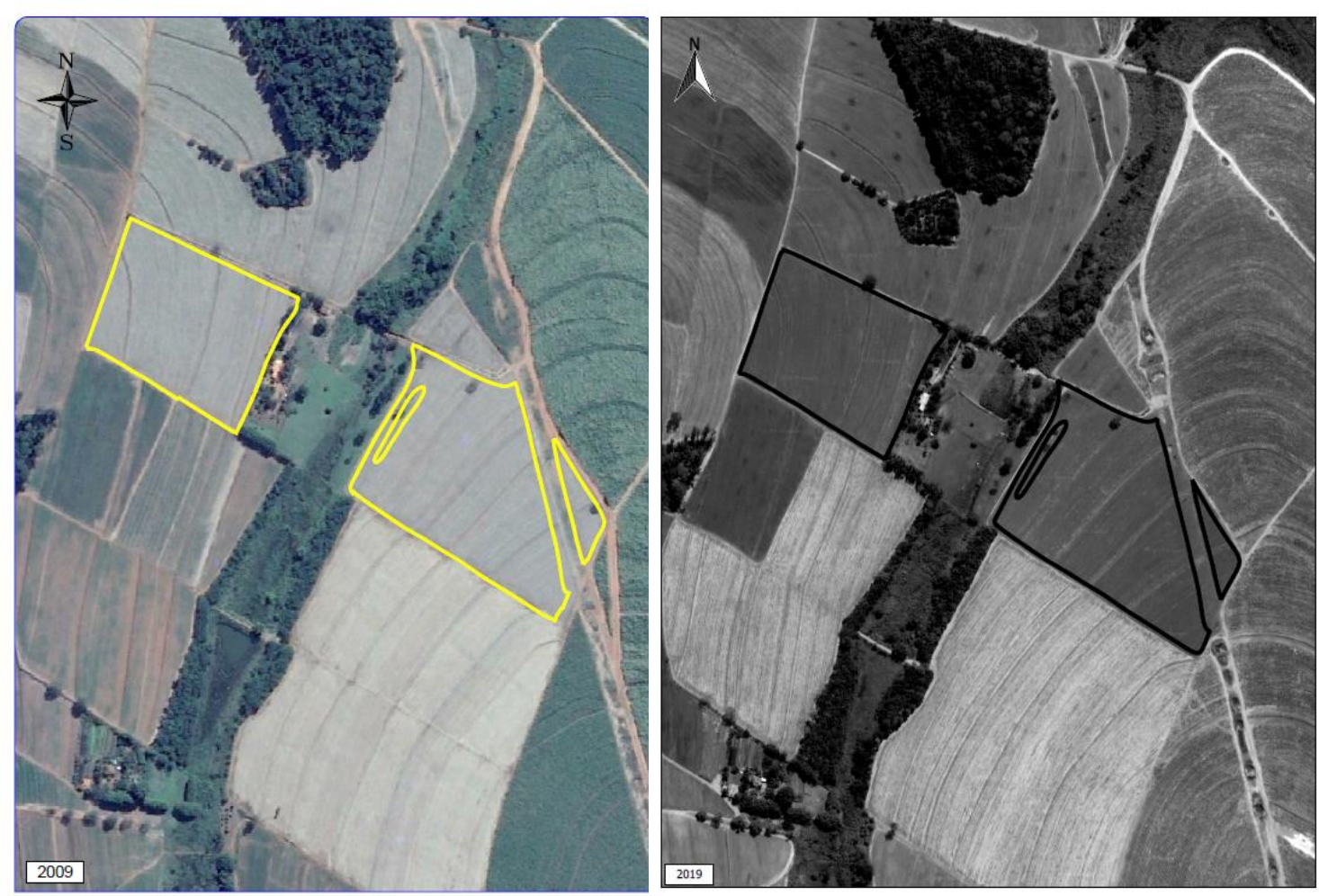

igura 8 -

Histórico

da

expansão

da área

de 12,36

ha

(Escala

$1: 5.000)$

Fonte: Elaborado pelo Autor. 
Figura 9 - Folha de rosto do Estudo de arrendamento.

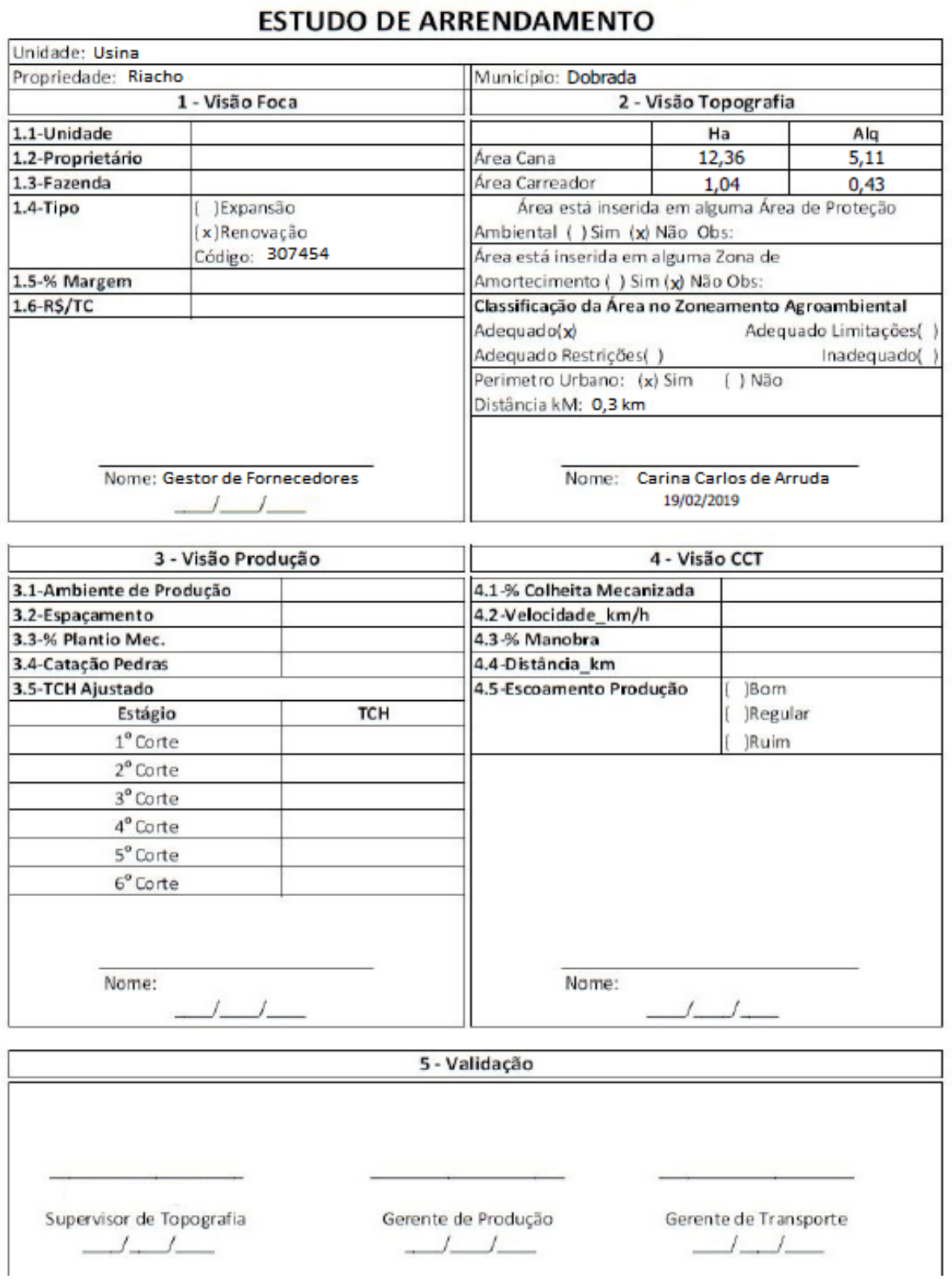

Fonte: Elaborado pelo Autor.

\section{CONCLUSÃO}

As ferramentas presentes nos Sistemas de Informação Geográfica QGIS permitiram a rápida detecção das áreas de interesse, permitindo a interpolação das áreas de preservação, áreas 
adequadas ou com fatores limitantes e a inserção no perímetro urbano, informações importantes a serem inseridas nos laudos.

A metodologia desenvolvida mostrou-se adequada para a tomada de decisão estratégica em projetos de renovação de áreas ou até mesmo em expansões, fornecendo ao operador uma série de opções para simulações de cenários, onde o mesmo pode considerar além das premissas destacadas, externalidades que excedem o modelo. Destacam-se como externalidades fatores como o desejo pessoal e específico de acionistas envolvidos com o negócio, pressão de terras exercidas por proprietários vizinhos, defesas de territórios, diferenças de comportamento de microclimas, dentre outros fatores.

\section{REFERÊNCIAS}

CARLESSO NETO, O.; VERÍSSIMO, M. P. Expansão da agricultura canavieira e a geração de energia alternativa no brasil. Horizonte Científico, v. 5, n. 1. 2018.

Confederação da Agricultura e Pecuária do Brasil - CNA, Ativos Cana-de-Açúcar: Custo de produção de cana-de-açúcar na região Centro-Sul - Safra 2016/17 / Julho 2017. Edição 15. 2017.

Conselho dos Produtores de cana-de-açúcar, açúcar e álcool do estado de São Paulo CONSECANA. 2006. Manual de Instruções. 5ed. CONSECANA, Piracicaba, São Paulo, Brasil. Disponível em <http://www.oricana.com.br/novosite/manual_consecana.pdf $>$. Acesso em 4 jul. 2019.

IEA. Instituto de Economia Agrícola. 2012. Banco de Dados. Disponível em: <http://www.iea.sp.gov.br/out/bancodedados.html>. Acesso em: fev. 2019.

KOHLHEPP, G. Análise da situação da produção de etanol e biodiesel no Brasil. Estudos avançados, v. 24, n. 68, p. 223-253, 2010.

NOVA CANA. Arrendar ou produzir, qual a melhor opção para a cana-de-açúcar? Disponível em: <https://www.novacana.com/n/cana/mercado/arrendar-produzir-opcao-cana230514> Acesso em: fev. 2019. 